\title{
Antiarrhythmic Medications for Cardioversion and Maintenance of Sinus Rhythm in Patients with Cardiac Arrhythmias: A Review of the Literature
}

\section{Guhl EN and Jain SK}

Center for Atrial Fibrillation, Heart and Vascular Institute, University of Pittsburgh Medical Center, USA

*Corresponding author: Sandeep K Jain, Center for Atrial Fibrillation, Heart and Vascular Institute, University of Pittsburgh School of Medicine, 200 Lothrop St. PUH B535, Pittsburgh, PA 15213, USA, Tel: 412-647-6272; Fax: 412-647-7979; E-mail: jainsk@upmc.edu

Received date: August 12, 2017; Accepted date: September 07, 2017; Published date: September 14, 2017

Copyright: (c) 2017 Guhl EN, et al. This is an open-access article distributed under the terms of the Creative Commons Attribution License, which permits unrestricted use, distribution, and reproduction in any medium, provided the original author and source are credited.

\section{Abstract}

Introduction: Cardiac arrhythmias, including supraventricular and ventricular tachycardias, portend a higher risk of morbidity and mortality. These arrhythmias also are associated with increased healthcare resource utilization, decreased quality of life, and increased activity impairment. Pharmacologic conversion is a treatment option for conversion to sinus rhythm that has the advantage of avoiding sedation from DC cardioversion.
\end{abstract}

Objective: To review the efficacy, side effects, clearance, and prescribing considerations for antiarrhythmic medications for pharmacologic cardioversion.

Methodology: We included studies evaluating the efficacy of antiarrhythmic drugs. We included prescribing indications including half-life, clearance, and side effects. We arranged the manuscript by Vaughan Williams classification.

Results: Class IA, class IC, and class III antiarrhythmic medications are effective at conversion of supraventricular arrhythmias with rates frequently greater than $50 \%$. Amiodarone and Lidocaine may be used for conversion of ventricular tachycardias. The specific agent utilized depends upon the potential other medication interactions, clearance and toxicity.

Conclusion: Pharmacologic cardioversion provides a reasonable alternative to electrical cardioversion in many cases.

Keywords: Pharmacologic cardioversion; Chemical cardioversion; Antiarrhythmic medications; Supraventricular tachycardia; Ventricular tachycardia; Atrial fibrillation

\section{Introduction}

Cardiac arrhythmias including supraventricular and ventricular tachycardias account for significant morbidity and mortality in the United States and contribute to increased overall healthcare resource utilization. It is currently estimated that 5.2 million adults in the United States have atrial fibrillation with the number expected to increase to 12.1 million by the year 2030 given the aging population [1]. Other types of supraventricular tachycardia have an incidence of 35 per 100,000 persons per year [2]. Ventricular arrhythmias are seen in $15-16 \%$ of individuals with coronary artery disease, $8-9 \%$ of individuals with other cardiovascular disease and in $2-3 \%$ of individuals with no cardiac disease and carry a high morbidity and mortality, particularly from sudden cardiac death [3]. In addition to increased morbidity and mortality, all of these cardiac arrhythmias portend decreased quality of life, increased activity impairment, and increased healthcare resource utilization $[4,5]$.

The goals of treatment differ slightly by type of arrhythmia but often involve rate control and conversion to sinus rhythm (SR) either by electrical cardioversion or with antiarrhythmic medications. For atrial fibrillation, maintenance of SR is also pursued by antiarrhythmic agents, and anticoagulants are utilized for prevention of stroke or thromboembolic events. Conversion to SR has multiple potential and theoretical benefits including alleviation of symptoms, improved hemodynamics, reduced risk of thromboembolic events, reduced morbidity and mortality, and lower healthcare resource utilization. When compared to electrical cardioversion, chemical cardioversion offers the advantage of not requiring sedation and typically medications that are successful for chemical cardioversion can be continued for maintenance of sinus rhythm.

The pathophysiology underlying cardiac arrhythmias has been studied extensively identifying many mechanisms that may serve as targets for therapy. Ion channel and transporter abnormalities lead to ectopic impulse formations making ion channels a common target for many of our current therapies [6]. Structural remodeling, particularly fibrosis, interferes with electrical activity making fibrosis formation a potential therapeutic target as well. Genome-wide association studies for atrial fibrillation have identified genetic loci that may be targets for gene therapies and personalized medicine [7]. MicroRNAs have been linked to cardiac excitability and structural remodeling [8]. Based on these mechanisms, novel therapy focusing on atrial-specific channel blockers, upstream therapy and remodeling are emerging for arrhythmias [9-11].

Due to electrophysiologic and structural remodeling that occurs with most arrhythmias, they generally become more difficult to convert with increasing duration. Thus, early conversion to SR may 
limit remodeling and improve efficacy of long-term treatment. In patients with hemodynamically unstable arrhythmias, electrical cardioversion is generally recommended. For this reason, many ventricular arrhythmias require electrical cardioversion given their instability though there are instances where antiarrhythmic medications can be used as an adjunct or alone if the patient is stable. In patients undergoing elective cardioversion, however, pharmacologic cardioversion may be preferred with the advantage of avoidance of potential side effects of pro-arrhythmia and sedation from DC cardioversion. However, when electing pharmacologic conversion, the side effects, clearance, and conversion efficacy of the medication used must be considered. Many of these drugs are also used for maintenance of sinus rhythm and if they fail then electrical cardioversion is generally pursued.

In the present article, we review the efficacy, side effects, clearance, and prescribing considerations of multiple antiarrhythmic medications for pharmacologic cardioversion and have organized the manuscript by Vaughan Williams classification. While Vaughan Williams classification is an imperfect classification system as most antiarrhythmic drugs have multiple modes of action, it does organize by primary mechanism and is currently the most widely accepted classification system. This review will focus on antiarrhythmic drugs for chemical cardioversion though many of the medications, particularly if successful for cardioversion, can be used for maintenance.

\section{Class IA Antiarrhythmic Medications}

\section{Procainamide}

Procainamide is a Vaughan Williams Class 1a antiarrhythmic agent approved for documented ventricular arrhythmias [12]. The mechanism of action involves inhibition of the rapid inward sodium current, INa. Procainamide metabolism occurs through hepatic metabolites, and elimination occurs through the renal system [13]. Procainamide has a reported reported half-life of 2.5-4.5 hours and carries a risk of hypotension, AV block, bradycardia, ventricular tachycardia, and systemic lupus erythematosus [14,15]. Nacetylprocainamide is an active metabolite of procainamide and itself has some Class III anti-arrhythmic properties [16].

Intravenous procainamide has a conversion efficacy for supraventricular tachycardias ranging from 11\%-65\% [14,17-20]. When divided by type of arrhythmia, the conversion rates are improved for atrial fibrillation vs. atrial flutter (42-58\% vs. 14-28\%). Halpern et al found that non-converters had a significantly larger left atrial size when compared to converters $(4.9 \mathrm{~cm}$ vs. $3.0 \mathrm{~cm})$ [20], while Fenster et al. found that converters had a significantly shorter mean duration of atrial fibrillation (6 vs. 79 days) [19]. Volgman et al. found a mean time to conversion of 34.4 minutes [17] and Stiell et al found a median time to conversion of 55 minutes [14].

Procainamide was found to be inferior for conversion efficacy of acute onset $(<24$ hours) atrial fibrillation when compared to flecainide (65\% vs. 92\%) [18]. The drug was also found to be inferior to ibutilide in conversion of both atrial flutter ( $14 \%$ vs. $76 \%$ ) and atrial fibrillation (21\% vs. $51 \%)$ [17]. There was no difference in conversion efficacy of atrial tachycardia for procainamide vs. amiodarone in the critically ill (71\% vs. $70 \%)$ [21].

Due to side effects and concern of pro-arrhythmia in patients with significant structural heart disease, use of Class IA agents is currently limited. Rapidly conducting atrial fibrillation in the setting of WolffParkinson-White Syndrome is a situation in which procainamide can be useful due to effects on the accessory pathway, atrial tissue and AV node.

\section{Quinidine}

Quinidine is a Vaughan Williams Class IA antiarrhythmic agent that has a mechanism of action similar to procainamide involving primarily inhibition of the rapid inward sodium current, INa but also with calcium and potassium channel blocking properties [22]. Quinidine is cleared by $60-85 \%$ by the liver, has a reported half-life of 3-19 hours and steady state plasma level achieved within 24 hours. Quinidine does carry a risk of proarrhythmia including Torsades de Pointes with a risk of $1.5 \%$ per year [23]. The most commonly reported side effects are gastrointestinal $[24,25]$. There is also a small but significant risk of immune-mediated drug effects including systemic lupus and vasculitis [26].

The conversion efficacy of quinidine for atrial fibrillation has been studied both alone and in conjunction with other medications. When administering quinidine alone, the conversion efficacy ranged from $40-84 \%$ [24,25,27]. Quinidine administered with digoxin had an efficacy range of $47-86 \%[28,29]$. When administered with propranolol, Antonelli et al found the conversion efficacy rate to be $88 \%$. (Antonelli et al., 1985) The mean time to conversion ranged from $4.0 \pm 2.9$ hours for quindine and digoxin to $10.8 \pm 10.5$ hours for quinidine alone $[28,30]$.

When compared to propafenone in patients with persistent atrial fibrillation of $<6$ months, quinidine was superior in conversion to sinus rhythm ( $84 \%$ vs. $28 \%$ ) [27]. Hohnloser et al compared quinidine to sotalol for conversion of atrial fibrillation to sinus rhythm and found quinidine to be superior to sotalol (60\% vs. 20\%) [24]. Borgeat et al compared quinidine to flecainide and found conversion rates of $60 \%$ vs. $67 \%$, however, when looking at $\mathrm{AF}$ that has lasted longer than 10 days quinidine was superior to flecainide ( $40 \%$ vs. $22 \%$ ) [25]. Kerin et al. compared quinidine with digoxin to amiodarone for conversion of persistent ( $>3$ weeks) atrial fibrillation finding no significant difference between the groups ( $47 \%$ vs. $44 \%$ ) [29].

The conversion efficacy of quinidine with digoxin has been evaluated in two studies. Halinen et al compared efficacy of sotalol to quinidine and in the quinidine group administered digoxin if the ventricular rate was $>100 \mathrm{bpm}$. The quinidine group demonstrated superior efficacy to sotalol for conversion of atrial fibrillation to sinus rhythm ( $86 \%$ vs. $52 \%)$ [28]. Capucci et al looked at recent onset atrial fibrillation, $<8$ days, and found that quinidine administered with digoxin was inferior to propafenone ( $48 \%$ vs. $83 \%$ ) [30].

\section{Class IB Antiarrhythmic Medications}

\section{Lidocaine}

Lidocaine is a Vaughan Williams Class IB antiarrhythmic agent approved as a first line agent for ventricular tachycardia. Lidocaine is CYP3A4-mediated and cleared by the hepatic system. The drug has a reported half-life of 87-108 minutes [31]. Toxic levels of lidocaine can produce CNS side effects including parasthesia, drowsiness and seizures as well as cardiovascular effects including sinus slowing, asystole, hypotension and shock. Though the risk of side effects with lidocaine is small at about $6 \%$, patients who are elderly, have structural 
heart disease or decreased hepatic clearance are more likely to experience side effects [32].

Lidocaine has not been shown to be effective in treatment of supraventricular tachycardias. Marrouche et al looked at efficacy for conversion of atrial fibrillation with high dose $(1.5-2.0 \mathrm{mg} / \mathrm{kg})$ lidocaine compared to placebo in 20 patients in a randomized doubleblind crossover study and found that none of the patients with placebo or lidocaine converted to AF [33].

While lidocaine has been the standard of care for ventricular fibrillation and ventricular tachycardia the evidence for its use is mixed with limited data from randomized trials. When lidocaine was compared to bretylium as a first line antiarrhythymic for refractory VF, lidocaine had a higher conversion rate ( $56 \%$ vs. $35 \%)$ but there was no significant difference in resuscitation or survival [34]. Haynes et al also looked at lidocaine in management of out of hospital VF compared to bretylium and found no significant difference in conversion to an organized rhythm ( $93 \%$ vs. $89 \%)$, perfusing rhythm ( $60 \%$ vs. $58 \%$ ), or survival to hospital discharge (26\% vs. $34 \%$ ) [35].

In a randomized trial, ALIVE, comparing lidocaine to amiodarone as an adjunct to defibrillation in patients with out of hospital cardiac arrest, there was significantly increased surivial to hospital admission with amiodarone when compared to lidocaine (23\% vs. $12 \%$ ) [36], Ohshige et al. looked at use of lidocaine and epinephrine vs. epinephrine alone in patients with VF who experienced out of hospital cardiac arrest and found improved survival to discharge [37]. A similar study also found the use of lidocaine to improve chance of survival to hospitalization after out of hospital cardiac arrest with VF (38\% vs. $18 \%)$, however, they did not find an improvement in survival until discharge. Both of these studies were confounded by the fact that the lidocaine had to be administered by a physician onboard EMS and in the cases without lidocaine administered there was not a physician.

A few studies question the benefit of lidocaine as treatment for cardiac arrest due to ventricular fibrillation. Weaver et al found that there was no difference in survival between patients receiving lidocaine vs. epinephrine during treatment for VF (19\% vs. 20\%) but survival was highest in patients who received no drug therapy (30\%) possibly due to lack of delay of subsequent defibrillation shocks [38]. Herlitz et al. found in a retrospective review that treatment with lidocaine was associated with a higher rate of return of spontaneous circulation but not an increased rate of discharge from the hospital [39].

\section{Class IC Antiarrhythmic Medications}

\section{Flecainide}

Flecainide is a Vaughan Williams Class IC antiarrhythmic agent approved for treatment of paroxysmal supraventricular tachycardias [40]. The mechanism of action is blockade of the cardiac fast inward $\mathrm{Na}$ current, INa, and the rapid component of the delayed rectifier $\mathrm{K}^{+}$, IKr, current [41]. Flecainide undergoes extensive hepatic biotransformation via cytochrome P450 CYP2D6 with inactive metabolites, making up about $85 \%$, excreted by the urine. The oral form has a bioavailability of $90-95 \%$ and the drug has a reported half life of 12-27 hours [42]. The drug has reported side effects of paresthesias, drowsiness, nausea, ventricular tachycardia, and sinus bradycardia [43]. Additionally, severe arrhythmogenic events have been shown to occur in $\sim 9 \%$ of patients on flecainide with patients having events tending to be older and have a longer baseline QRS duration $[44,45]$.
Muhiddin et al. suggest that flecainide may even slightly reduce cardiac output after infusion [46]. The Cardiac Arrhythmia Suppression Trial found that the rates of non-fatal ischemic events between placebo and treatment (flecainide or encainide) were the same at $21 \%$ in 1 year but the treatment group had a much greater mortality rate when compared to placebo in patients with recent MI [47-49], and therefore flecainide should be avoided in patients with structural heart disease.

Trials evaluating the conversion efficacy of flecainide have focused on patients with recent-onset (less than 1 week) supraventricular tachyarrhythmias with a reported conversion efficacy ranging from 59-95\%. [18,50-54], Martinez-Marcos et al found the median time to conversion to be 25 minutes with a range of 4-660 minutes.

When Camm et al compared different supraventricular tachyarrhythmias: atrial fibrillation (90\%), atrial tachycardia (100\%), AV node reentry tachycardia (89\%) and atrioventricular re-entrant tachycardia $(80 \%)$ are generally terminated with a greater efficacy than atrial flutter (20\%) [55]. Crozier et al. also noted decreased rates of conversion for atrial flutter or atrial reentrant tachycardia (42\%) when compared with AF (76\%) or AVRT (100\%) [43].

When comparing intravenous and oral formulations, Crijns et al. found no difference in efficacy of oral vs. intravenous formulations of flecainide for acute conversion of atrial fibrillation to sinus rhythm while Alp et al did find that IV flecainide restores SR after acute AF more rapidly than oral flecainide but after 2 and 8 hours there were no significant differences [56,57].

When compared to other medications, intravenous flecainide had significantly higher conversion efficacy compared to verapamil $(82 \%$ vs. $6 \%$ ) [54], amiodarone (59\% vs. $22 \%$ ) [53], and (90\% vs. 60\%)[58], procainamide (95\% vs. $65 \%$ ) [18], and propafenone. (90\% vs. $72 \%$ ) [58].

A single loading dose of oral flecainide at $300 \mathrm{mg}$ had a superior conversion efficacy to placebo ( $91 \%$ vs. $48 \%$ ) and amiodarone ( $91 \%$ vs. $37 \%)$ in 8 hours [51].

\section{Propafenone}

Propafenone is a Vaughan Williams Class IC antiarrhythmic agent approved for prolongation of the time to recurrence of paroxysmal atrial fibrillation/flutter and paroxysmal supraventricular tachycardia. It is a potent sodium channel blocker with weak beta-adrenergic and calcium channel blocking activity [59]. Propafenone is $~ 99 \%$ cleared by the hepatic system and has a reported half-life of 2-12 hours [59-61]. The drug is contraindicated in patients with hepatic dysfunction, brochospastic disorder [62], heart failure [63,64], or bradycardia and is therefore rarely utilized in patients with significant structural heart disease. Reported side effects include hypersensitivity reactions, lupus-like syndrome, agranulocytosis, CNS disturbances, lightheadedness, a metallic taste and bronchospasm $[59,65,66]$.

Approximately 7-10\% of Caucasians, 2-7\% of African Americans, and $1 \%$ of Asians lack the capacity to metabolized CYP2D6 substrates and are classified as poor metabolizers. Increased exposure may lead to cardiac arrhythmias and exaggerated beta-adrenergic blocking activity and thus because of propafenone's metabolism by CYP2D6, the deficiency of this isoenzyme is potentially hazardous $[67,68]$.

When studying conversion after a single loading oral dose of propafenone, the conversion rate ranged from $57 \%$ to $86 \%$ depending on the follow-up after administration of propafenone [30,69-74]. Most 
studies have utilized a single oral dose of $600 \mathrm{mg}[30,71,73,74]$, however Azpitarte used a dose of 450, 600 or $750 \mathrm{mg}$ based on weight and Botto et al used either 450 or $600 \mathrm{mg}$. When comparing the 450 and $600 \mathrm{mg}$ doses, Botto et al found that the conversion rate for the $600 \mathrm{mg}$ dose was superior at $2 \mathrm{hr}(43 \%$ vs. $8 \%)$ but not at $8 \mathrm{hr}(57 \%$ vs. $46 \%)$ [70]. Boriani et al found the conversion rate of oral propafenone was $55 \%$ compared to IV propafenone at $41 \%$ though this was not statistically significant [73]. Later, Botto et al did find that while IV propafenone was more effective than oral at 1 hour ( $48 \%$ vs. $15 \%)$, there was a significantly higher conversion rate for oral vs. IV propafenone at 8 hours. ( $78 \%$ vs. $48 \%$ at 8 hours, $\mathrm{p}<0.01)$ [75].

Multiple studies found propafenone to be superior to placebo for CCV at all-time points studied [30], however two studies found that propafenone was superior to placebo in the short-term but not the long-term [70]. Azipitarte et al. found propafenone to be superior at 1 and 6 hours but not 12 or 24 hours. Botto et al. found propafenone was superior at 2 hours, 4 hours, and 8 hours but not at 24 hours. The drug was also found to be superior to digoxin plus quinidine at 12 hours ( $83 \%$ vs. $48 \%, \mathrm{p}<0.05)$ [30] and to digoxin alone [72]. The mean time to conversion for propafenone ranged from $110 \pm 59 \mathrm{~min}$ [70] to $267 \pm$ $238 \min [30,70,71,73,74]$.

\section{Class III Antiarrhythmic Medications}

\section{Amiodarone}

Amiodarone is an antiarrhythmic agent approved for life threatening ventricular tachyarrhythmia and atrial arrhythmias. Although specified as a class III Vaughan Williams antiarrhythmic with inhibition of outward potassium channels, it also has significant class I and class II activity. Amiodarone is tacked up quickly and extensively by the extravascular tissues giving the intravenous form a short half life but a long elimination period [76]. However, after long term oral therapy, it has a half life of up to 60 days [77]. The drug has demonstrated safety in patients with structural heart disease and severe left ventricular hypertrophy but it does carry a risk of hypotension (11.1\%)[78], phlebitis at the infusion site with the IV form (15.7\%) [78], abnormalities in thyroid function (1.2\%) elevated hepatic enzyme levels (1.2\%), and severe pulmonary fibrosis (1.2\%) [79]. Singh et al. found that there was no significant difference in overall mortality for amiodarone vs. placebo in patients with congestive heart failure and asymptomatic ventricular arrhythmia [80].

The conversion for SVT with amiodarone has been reported to range from $47 \%-80 \%[52,78,80,81]$, with a median time to conversion of 5.5-8.7 hours [52,80,81].

Amiodarone has been shown to be superior to placebo in conversion of atrial fibrillation in multiple randomized clinical trials. Vardas et al. found amiodarone superior to placebo in conversion of AF ( $80 \%$ vs. $40 \%$ ) with patients who successfully converted having a short median AF duration (14 hours vs. 1440 hours) [78].

Similarly, Peuhkurinen et al. found amiodarone to be superior to placebo ( $50 \%$ vs. $20 \%$ ) in patients with recent-onset ( $<48$ hours) AF [81]. Amiodarone has been reported to have lower conversion rates compared to flecainide and propafenone (64\% vs. $90 \%$ vs. $72 \%)$ [52], in patients with recent onset AF but it does carry the advantage of being first-line therapy approved for special patient populations including those with heart failure or severe left ventricular hypertrophy [82].

Amiodarone is widely used and effective for ventricular arrhythmias. As discussed previously, amiodarone was compared to lidocaine in the treatment of out-of-hospital ventricular fibrillation in the ALIVE trial and found to lead to substantially higher rates of survival to hospital admission [36].

\section{Dofetilide}

Dofetilide is a Vaughan Williams Class III antiarrhythmic agent approved for maintenance of sinus rhythm in patients with atrial fibrillation (AF) or atrial flutter (AFL) and for chemical cardioversion to sinus rhythm. The mechanism of action is blockade of the delayed rectifier potassium current, IKr. Dofetilide is $\sim 80 \%$ cleared by the renal system, has a reported half-life of $\sim 10$ hours and steady state plasma level achieved in 2-3 days [83].

The drug has demonstrated both safety and efficacy in patients with coronary artery disease [84], and left ventricular dysfunction [85-87], but it does carry a risk of QT prolongation and Torsades de Pointes (TdP) and thus requires in-hospital initiation for 6 doses on continuous telemetry with QT monitoring on 12-lead ECGs after each dose. Initial dosing should be based on $\mathrm{CrCl}$ and adjusted with changing renal function or QTc prolongation. In the landmark SAFIRE-D trial, dose adjustments were required in $33 \%$ of patients due to change in $\mathrm{CrCl}$ or prolonged QTc [88].

The incidence of $\mathrm{TdP}$ in patients on dofetilide ranges from $0.9 \%-3.3 \%[85,87,88]$. The DIAMOND trials were a set of randomized, intention-to-treat, double-blind, placebo-controlled trials that evaluated the efficacy of dofetilide in high risk patients with either heart failure (DIAMOND-CHF) [85], or recent MI (DIAMOND-MI) [87]. Dofetilide was found to have a neutral all-cause morality risk of $41 \%$ vs. $42 \%$ reported in DIAMOND-CHF[85] and $31 \%$ vs. $32 \%$ reported in DIAMOND-MI [87], compared to placebo. Abraham et al noted risk factors, however, for an increase in one-year mortality including patients with TdP during loading compared to those without ( $17.6 \%$ vs. $3 \%$ at 1 year) [89]. Bendorp et al. found that baseline QTc $<420 \mathrm{~ms}$ was associated with a marked reduction in mortality in patients with LV systolic dysfunction (RR 0.4, 95\% CI 0.3-0.8) and that there was an increased risk of mortality with a baseline QTc $>479 \mathrm{~ms}$ (RR 1.3, 95\% CI 0.8 to 1.9) [90]. Pedersen et al. further expanded on the risk factors for TdP in patients on dofetilide with another DIAMOND-HF substudy. They found in addition to baseline QTc (OR $1.14,95 \%$ CI $1.00-1.30$ per $10 \mathrm{~ms}$ ), that female gender (OR 2.2, CI 1.0-5.0) and NYHA Class III or IV HF (OR 3.2, CI 1.2-8.6) were risk factors for TdP [91].

Rates of successful CCV with dofetilide have been reported to range from $29 \%-77 \%$ [88,92-95], and typically takes $\sim 2 \pm 1$ doses for conversion $[92,93,95]$, with $21 \%$ of patients converting after the first dose of the drug [92]. Multiple studies have noted the rate of chemical cardioversion (CCV) to increase in a dose-dependent manner, the SAFIRE-D trial noted rates of $29.9 \%$ for $500 \mathrm{mcg}$ BID, $9.8 \%$ for 250 mcg BID and 6.1\% for $125 \mathrm{mcg}$ BID [88,93]. Dofetilide has been noted to be more effective for CCV in AFL than AF with reported comparisons of $65 \%$ vs. $25 \%$ [95], and $75 \%$ vs. $22 \%$ [96].

Malhotra et al. studied CCV during loading vs. DC cardioversion (DCCV) for durability of maintaining sinus rhythm and found that CCV was an important predictor of durable response when compared to DCCV [97]. After CCV to SR with dofetilide, reports of the rate of maintenance of sinus rhythm at one year range from $\sim 1 / 3$ of patients to $58 \%[88,94]$. Our group found that patients who converted to sinus rhythm (SR) after a single dose had a higher risk of toxicity vs. those who converted at subsequent doses with $71 \%$ of those who converted 
after 1st dose developing significant QT prolongation requiring dose adjustment [92].

\section{Ibutilide}

Ibutilide is a Vaughan Williams Class III antiarrhythmic agent approved for the treatment of atrial fibrillation and atrial flutter [98]. The mechanism of action is increase in action potential duration by blocking the rapid component of the cardiac delayed rectifier current, $\mathrm{IKr}[98,99]$. Ibutilide is intravenously delivered given its high first pass metabolism resulting in poor bioavailability of the oral form. Ibutilide has a high systemic plasma clearance that approximates liver blood flow[100], is excreted by the renal system and has a reported half-life of 2-12 hours [98].

The drug has demonstrated both safety and efficacy in patients heart failure [100], however, given that ibutilide causes a dose- and concentration related increase in QT interval, it does carry a risk of $\mathrm{TdP}$ in $\sim 4-8.3 \%$ of patients $[100,101]$, and extrasystole in $4.8-9 \%$ of patients $[17,98,102]$.

The conversion rate for ibutilide for SVT has been reported to be from $31 \%-58 \%$ [100-103] with improved conversion of atrial flutter over atrial fibrillation (61-76\% vs. $31-51 \%)$ [101]. Patsillinakos et al looked at the concomitant administration of magnesium with ibutilide and found that the addition of magnesium lead to a $13.7 \%$ improvement in the success rate of conversion with ibutilide [104]. The mean conversion time to SR after ibutilide administration ranges from 13-25 minutes [17,102].

Multiple studies have found ibutilide to be superior to placebo for conversion of AF and AFL [100,101]. When compared to procainamide, Volgman et al. found that ibutilide was more effective for the conversion of AF and AFL to SR $(58.3 \%$ vs. $18.3 \%, \mathrm{p}<0.0001)$ [17]. Vos et al. compared ibutilide efficacy to sotalol finding ibutilide superior for both AFL ( $70 \%$ vs. $19 \%)$ and AF ( $44 \%$ vs. $11 \%, \mathrm{p}<0.01)$ [102]. Standard administration of ibutilide requires close monitoring for 4-6 hours in a unit with continuous telemetry able to provide rapid external defibrillation due to the risk of tdP.

\section{Sotalol}

Sotalol is a non-selective is a nonselective $\beta$-Blocker with Vaughan Williams Class III activity antiarrhythmic agent approved for maintenance of sinus rhythm in patients with symptomatic atrial fibrillation or flutter and treatment of documented life-threatedning ventricular arrhythmias $[105,106]$. The oral form is almost $100 \%$ bioavailable with $0 \%$ binding to plasma proteins and the half-life is 10-20 hours. Sotalol and is renally excreted and thus the daily dose must be reduced in renal failure [107].

The major risk is of torsades de pointes due to QT prolongation with studies showing a dose dependent increase in QT and QTc $[105,108]$. It also is associated with fatigue, lightheadedness, headache, weakness, nausea, shortness of breath and bradycardia. The drug should be avoided or used with caution in conjunction with other QT prolonging agents. Sotalol is often initiated as an inpatient to allow monitoring for pro-arrhythmia and QT prolongation but has been shown to be feasible as an outpatient with transtelephonic monitoring $[108,109]$.

The conversion efficacy for sotalol varies dependent on arrhythmia with efficacy rates reported for SVT of $67-86 \%$ [110,111], atrial fibrillation conversion rates of $11-52 \%$, and an atrial flutter conversion rate of $24 \%$ Mean time to conversion with sotalol is $10.2 \pm 7.6$ hours [28,102,111,112].

When compared to placebo, sotalol has an increase conversion efficacy rate for SVT (67\% vs. $14 \%$ ) [110], but not AF (11\% vs. $14 \%)$ [111]. Additionally sotatol demonstrated decreased efficacy for conversion of AF when compared to quinidine (52\% vs. $86 \%$ ) [28], and ibutilide (11\% vs. $44 \%)$ [102]. In the SAFE-T trial atrial fibrillation conversion and maintenance efficacy of amiodarone vs. sotalol was studied in a double blind placebo-controlled trial. Sotalol and amiodarone were similar in conversion efficacy $(24.2 \%$ vs. $27.1 \%)$ and superior to placebo $(0.8 \%)$, however, amiodarone was superior to sotalol for long-term maintenance of sinus rhythm [112].

\section{Vernakalant}

Vernakalant, a novel antiarrhythmic, is an atrial-selective and mixed dose-, rate- and voltage-dependent $\mathrm{Na}^{+}$and $\mathrm{K}^{+}$channel blocker [113]. Due to its high affinity to ion channels in atrial over ventricular tissue, it is thus thought to have a lower proarrhythmic potential than other antiarrhythmic medcations. Vernakalant has been approved for pharmacologic cardioversion of recent-onset $\mathrm{AF}$ ( $\leq 7 \mathrm{day}$ ) and postoperative AF ( $\leq 3$ days) in the European Union but is not yet approved in the US. The drug is contraindicated in patients with hypotension $(\mathrm{SBP}<100)$, severe aortic stenosis, NYHA III and IV heart failure, QT prolongation, or acute coronary syndrome in the past 30 days. Vernakalant is associated with dysgeusia (7-19\%), sneezing (3-16\%), cough (3-6\%) hypotension (1-20\%), QT prolongation, and bradycardia (2-14\%) [114-117].

A series of double-blind, placebo-controlled phase III trials were performed randomized to vernakalant vs. placebo (ACT I-III) $[114,116,117]$ with 336,160 and 262 patients, respectively. The ACT I and III studies evaluated patients with recent-onset AF while ACT II focused the conversion efficacy in post-operative patients (1-7 days) for CABG or valvular surgery. All three studies found vernakalant to be superior to placebo; ACT I ( $52 \%$ vs $4 \%$ ), ACT II ( $47 \%$ vs. $14 \%$ ) and ACT III (51\% vs 3.6\%) when considering patients converted from AF to SR within 90 minutes. The median time to conversion ranged from 8-12 minutes and $75 \%-82 \%$ of those who converted did so after the first dose [116,117].

ACT IV was an open-label phase IV trial looking at 167 patients with a conversion efficacy of $51 \%$ and a median time to conversion of 14 minutes [115]. There was an improvement in conversion rates for patients with $\mathrm{AF} \leq 48 \mathrm{hrs}$ vs. $>7$ days ( $57.9 \%$ vs $11.6 \%$ ). In the ARVO trial, a Phase III trial comparing efficacy of vernakalant to amiodarone, vernakalant was found to be superior for rapid conversion of AF to SR (51.7\% vs. $5.2 \%$ conversion in first $90 \mathrm{~min}$ ) with a median conversion time of 11 minutes [114]. The patients in the ARVO trial also reported improvement in reduction of symptoms at 2 hours with vernakalant $(53.4 \%$ vs. $32.8 \%)$.

\section{Class V Antiarrhythmic Medications}

\section{Adenosine}

Adenosine is an antiarrhythmic agent approved for diagnosis and treatment of supraventricular tachycardia. Adenosine is an endogenously occurring nucleoside whose antiarrhythmic action is mediated at the cellular level through potassium channels leading to hyperpolarization of the membrane potential in atrial myocytes [118]. In addition to coronary vasodilation, adenosine also depresses SA and 
Citation: Guhl EN, Jain SK (2017) Antiarrhythmic Medications for Cardioversion and Maintenance of Sinus Rhythm in Patients with Cardiac Arrhythmias: A Review of the Literature. Cardiovasc Pharm Open Access 6: 218. doi:10.4172/2329-6607.1000218

Page 6 of 10

AV node activity, atrial contractility, and ventricular automaticity [119]. The drug is administered intravenously and has an extremely short half-life of 0.6-1.5 seconds making most adverse reactions clinically insignificant. [119,120].

The drug is most commonly associated with dose-dependent symptoms of dyspnea, flushing and chest discomfort but symptoms typically last less than 60 seconds [119-121]. Rare side effects include bronchospasm, atrial fibrillation, and NSVT. In addition to treatment of paroxysmal supraventricular tachycardias, adenosine plays a role in diagnosis. The drug terminates the vast majority of AV node dependent tachycardias producing AV block that will reveal intratrial arrhythmias. DiMarco et al demonstrated high specificity and sensitivity as well as safety of adenosine in the diagnosis of patients presenting with narrow-complex tachycardia by distinguishing between atrial tachycardias and those that require the $\mathrm{AV}$ node $[122,123]$.

The conversion efficacy at doses of $3,6,9$, and $12 \mathrm{mg}$ cumulative adenosine respectively is $35.2 \%, 62.3 \%, 80.2 \%$, and $91.4 \%$ [124]. Other studies found similar results with the cumulative efficacy ranging from $94-100 \%[125,126]$. When compared to verapamil for the conversion of paroxysmal SVT to SR, DiMarco et al found that adenosine was similar in efficacy but more rapid in onset of action. Two additional retrospective studies also looked at termination of paroxysmal SVT with adenosine vs. verapamil and found that adenosine had a slightly higher success rate in conversion efficacy ( $94 \%$ vs. $81 \%$ ) [126], and (100\% vs. $91 \%$ ) [125]. Adenosine offers some potential advantages to verapamil including faster onset of action, short half-life resulting intransient duration of side effects, and relative absence of adverse hemodynamic effects.

\section{Conclusion}

Pharmacologic cardioversion provides a reasonable alternative to electrical cardioversion in many cases. As outlined, the specific agent utilized often depends upon the potential other medication interactions, clearance and potential toxicity.

The results of our review show that class IA, class IC, and class III antiarrhythmics are effective at conversion of supraventricular arrhythmias with rates frequently greater than 50\%. (Table 1) Randomized controlled trials for ventricular arrhythmias are more difficult to perform given the ethics of deviating from the current standards due to the life-threatening nature of these arrhythmias.

Novel therapies targeting fibrosis formation, upstream therapies, gene therapy and personalized medicine are emerging as potential treatments for arrhythmias. Continued drug development will be important to enhance efficacy of conversion in addition to minimizing toxicity, as there still exist significant unmet needs in this field.

\begin{tabular}{|c|c|c|c|c|}
\hline & Half Life & Clearance & Conversion Rate & Side Effects \\
\hline \multicolumn{5}{|l|}{ Class IA } \\
\hline Procainamide & 2.5-4.5 hours & renal & AF: $42-58 \%$ AFL: $14-28 \%$ & $\begin{array}{l}\text { hypotension, AV block, } \quad \text { bradycardia, } \\
\text { ventricular tachycardia, systemic lupus erythematous }\end{array}$ \\
\hline nQuinidine & $3-19$ hours & hepatic, renal & AF: $40-84 \%$ & $\begin{array}{l}\text { proarrhythmia including TdP, gastrointestinal side effects, } \\
\text { systemic lupus erythematous, vasculitis }\end{array}$ \\
\hline \multicolumn{5}{|l|}{ Class IB } \\
\hline Lidocaine & $87-108$ minutes & hepatic & VT/VF: $56-93 \%$ & sinus slowing, asystole, hypotension, shock \\
\hline \multicolumn{5}{|l|}{ Class IC } \\
\hline Flecainide & $12-27$ hours & hepatic, renal & SVT: $59-95 \%$ & $\begin{array}{l}\text { paresthesias, drowsiness, nausea, ventricular tachycardia, } \\
\text { sinus bradycardia }\end{array}$ \\
\hline Propafenone & $2-12$ hours & hepatic & SVT: $57-86 \%$ & $\begin{array}{l}\text { hypersensitivity reactions, lupus-like syndrome, } \\
\text { agranulocytosis, CNS disturbances, lightheadedness, } \\
\text { metallic taste }\end{array}$ \\
\hline \multicolumn{5}{|l|}{ Class III } \\
\hline Amiodarone & $\begin{array}{l}\text { IV: } 3-80 \text { hours Oral } 60 \\
\text { days }\end{array}$ & hepatic & SVT: $47 \%-80 \%$ VT/VF & $\begin{array}{l}\text { hypotension, phlebitis at injection site, thyroid } \\
\text { abnormalities, pulmonary toxicity, elevated hepatic enzyme } \\
\text { levels }\end{array}$ \\
\hline Dofetilide & 10 hours & renal, hepatic & SVT: $29-77 \%$ & proarrhythmia including TdP \\
\hline Ibutilide & $2-12$ hours & hepatic & SVT: $31-58 \%$ & proarrhythmia including TdP \\
\hline Sotalol & $10-20$ hours & renal & $\begin{array}{l}\text { SVT: } 67-86 \% \text { AF: } 11-52 \% \\
\text { AFL: } 24 \%\end{array}$ & $\begin{array}{l}\text { fatigue, lightheadedness, weakness, nausea, bradycardia, } \\
\text { dyspnea, headache }\end{array}$ \\
\hline Vernakalant & 3-4 hours & renal, hepatic & AF: $47-52 \%$ & $\begin{array}{l}\text { dysgeusia, sneezing, cough, hypotension, QT } \\
\text { prolongation, bradycardia }\end{array}$ \\
\hline \multicolumn{5}{|l|}{ Class V } \\
\hline Adenosine & $0.6-1.5$ seconds & $\begin{array}{l}\text { converted to inosine and } \\
\text { AMP }\end{array}$ & SVT: $91-100 \%$ & $\begin{array}{l}\text { dyspnea, flushing, chest discomfort, bronchospasm, AF, } \\
\text { NSVT }\end{array}$ \\
\hline
\end{tabular}

Table 1: Summary of Antiarrhythmic Medications. 


\section{References}

1. Colilla S, Crow A, Petkun W, Singer DE, Simon T, et al. (2013) Estimates of current and future incidence and prevalence of atrial fibrillation in the U.S. adult population. Am J Cardiol 112: 1142-1147.

2. Orejarena LA, Vidaillet H, DeStefano F, Nordstrom DL, Vierkant RA, et al. (1998) Paroxysmal supraventricular tachycardia in the general population. J Am Coll Cardiol 31: 150-157.

3. Aronow WS, Ahn C, Mercando AD, Epstein S, Kronzon I (2002) Prevalence and association of ventricular tachycardia and complex ventricular arrhythmias with new coronary events in older men and women with and without cardiovascular disease. J Gerontol A Biol Sci Med Sci 57: 178-180.

4. Goren A, Liu X, Gupta S, Simon TA, Phatak H (2013) Quality of Life, Activity Impairment, and Healthcare Resource Utilization Associated with Atrial Fibrillation in the US National Health and Wellness Survey. PLoS ONE 8: 71264-71269.

5. Hsu J, Uratsu C, Truman A, Quesenberry C, McDonald KM, et al. (2002) Life after a ventricular arrhythmia. Am Heart J 144: 404-412.

6. Iwasaki YK, Nishida K, Kato T, Nattel S (2011) Atrial fibrillation pathophysiology: implications for management. Circulation. American Heart Association 124: 2264-2274.

7. Lubitz SA, Ozcan C, Magnani JW, Kaab S, Benjamin EJ, et al. (2010) Genetics of Atrial Fibrillation: Implications for Future Research Directions and Personalized Medicine. Circ Arrhythm Electrophysiol 3: 291-299.

8. Wang Z, Lu Y, Yang B (2011) MicroRNAs and atrial fibrillation: new fundamentals. Cardiovasc Res 89: 710-721.

9. Sirish P, Li N, Timofeyev V, Zhang XD, Wang L, et al. (2016) Molecular Mechanisms and New Treatment Paradigm for Atrial Fibrillation. Circ Arrhythm Electrophysiol. American Heart Association 9: e003721.

10. Savelieva I, Kakouros N, Kourliouros A, Camm AJ (2011) Upstream therapies for management of atrial fibrillation: review of clinical evidence and implications for European Society of Cardiology guidelines. Part I: primary prevention. Europace 13: 308-328.

11. Burashnikov A, Di Diego JM, Zygmunt AC, Belardinelli L, Antzelevitch C (2007) Atrium-Selective Sodium Channel Block as a Strategy for Suppression of Atrial Fibrillation: Differences in Sodium Channel Inactivation Between Atria and Ventricles and the Role of Ranolazine. Circulation 116: 1449-1457.

12. Mohamed AN, Abdelhady AM, Spencer D, Sowinski KM, Tisdale JE, et al. (2013) Pharmacokinetic Modeling and Simulation of Procainamide and N-Acetylprocainamide in a Patient Receiving Continuous Renal Replacement Therapy: A Novel Approach to Guide Renal Dose Adjustments. American Journal of Kidney Diseases 61: 1046-1048.

13. Dreyfuss J, Bigger JT, Cohen AI, Schreiber EC (1972) Metabolism of procainamide in rhesus monkey and man. Clin Pharmacol Ther 13: 366-371.

14. Stiell IG, Clement CM, Symington C, Perry JJ, Vaillancourt C, et al. (2007) Emergency department use of intravenous procainamide for patients with acute atrial fibrillation or flutter. Acad Emerg Med 14: 1158-1164.

15. Lawson DH, Jick H (1977) Adverse reactions to procainamide. Br J Clin Pharmacol 4: 507-511.

16. Harron DW, Brogden RN (1990) Acecainide (N-acetylprocainamide). A review of its pharmacodynamic and pharmacokinetic properties, and therapeutic potential in cardiac arrhythmias. Drugs 39: 720-740.

17. Volgman AS, Carberry PA, Stambler B, Lewis WR, Dunn GH, et al. (1998) Conversion efficacy and safety of intravenous ibutilide compared with intravenous procainamide in patients with atrial flutter or fibrillation. J Am Coll Cardiol 31: 1414-1419.

18. Madrid AH, Moro C, Marin-Huerta E, Mestre JL, Novo L, et al. (1993) Comparison of flecainide and procainamide in cardioversion of atrial fibrillation. European Heart Journal 14: 1127-1131.

19. Fenster PE, Comess KA, Marsh R, Katzenberg C, Hager WD (1983) Conversion of atrial fibrillation to sinus rhythm by acute intravenous procainamide infusion. Am Heart J 106: 501-504.

20. Halpern SW, Ellrodt G, Singh BN, Mandel WJ. Efficacy of intravenous procainamide infusion in converting atrial fibrillation to sinus rhythm. Relation to left atrial size. Br Heart J. BMJ Group 44:589-595.

21. Chapman MJ, Moran JL, O'Fathartaigh MS, Peisach AR, Cunningham DN (1993) Management of atrial tachyarrhythmias in the critically ill: a comparison of intravenous procainamide and amiodarone. Intensive Care Med. Springer Verlag 19: 48-52.

22. Grace AA, Camm AJ (1998) Quinidine. N Engl J Med 338: 35-45.

23. Roden DM, Woosley RL, Primm RK (1986) Incidence and clinical features of the quinidine-associated long QT syndrome: implications for patient care. Am Heart J 111: 1088-1093.

24. Hohnloser SH, van de Loo A, Baedeker F (1995) Efficacy and proarrhythmic hazards of pharmacologic cardioversion of atrial fibrillation: prospective comparison of sotalol versus quinidine. J Am Coll Cardiol 26: 852-858.

25. Borgeat A, Goy JJ, Maendly R, Kaufmann U, Grbic M, et al. (1986) Flecainide versus quinidine for conversion of atrial fibrillation to sinus rhythm. The American Journal of Cardiology 58: 496-498.

26. Cohen MG, Kevat S, Prowse MV, Ahern MJ (1988) Two distinct quinidine-induced rheumatic syndromes. Ann Intern Med 108: 369-371.

27. Capucci A (1998) Quinidine versus propafenone for conversion of atrial fibrillation to sinus rhythm. The American Journal of Cardiology 81: 373-374.

28. Halinen MO, Huttunen M, Paakkinen S, Tarssanen L (1995) Comparison of sotalol with digoxin-quinidine for conversion of acute atrial fibrillation to sinus rhythm (the Sotalol-Digoxin-Quinidine Trial). The American Journal of Cardiology 76: 495-498.

29. Kerin NZ, Faitel K, Naini M (1996) The efficacy of intravenous amiodarone for the conversion of chronic atrial fibrillation. Amiodarone vs quinidine for conversion of atrial fibrillation. Arch Intern Med 156: 49-53.

30. Capucci A, Boriani G, Rubino I, Casa Della S, Sanguinetti M, et al. (1994) A controlled study on oral propafenone versus digoxin plus quinidine in converting recent onset atrial fibrillation to sinus rhythm. International Journal of Cardiology 43: 305-313.

31. Collinsworth KA, Kalman SM, Harrison DC (1974) The Clinical Pharmacology of Lidocaine as an Antiarrhythymic Drug. Circulation. Lippincott Williams \& Wilkins 50: 1217-1230.

32. Pfeifer H (1976) Clinical use and toxicity of intravenous lidocaine. Clin Pharmacol Ther 19: 113-114.

33. Marrouche NF, Reddy RK, Wittkowsky AK (2000) High-dose bolus lidocaine for chemical cardioversion of atrial fibrillation: a prospective, randomized, double-blind crossover trial. Am Heart J 139: 8-11.

34. Olson DW, Thompson BM, Darin JC (1984) A randomized comparison study of bretylium tosylate and lidocaine in resuscitation of patients from out-of-hospital ventricular fibrillation in a paramedic system. Annals of emergency 13: 807-810.

35. Haynes RE, Chinn TL, Copass MK, Cobb LA (1981) Comparison of bretylium tosylate and lidocaine in management of out of hospital 
ventricular fibrillation: a randomized clinical trial. Am J Cardiol 48 353-356.

36. Dorian P, Cass D, Schwartz B, Cooper R, Gelaznikas R, et al. (2002) Amiodarone as compared with lidocaine for shock-resistant ventricular fibrillation. 346: 884-890.

37. Ohshige K, Shimazaki S, Hirasawa H, Nakamura M, Kin H, et al. (2005) Evaluation of out-of-hospital cardiopulmonary resuscitation with resuscitative drugs: a prospective comparative study in Japan. Resuscitation 66: 53-61.

38. Weaver WD, Fahrenbruch CE, Johnson DD, Hallstrom AP, Cobb LA, et al. (1990) Effect of epinephrine and lidocaine therapy on outcome after cardiac arrest due to ventricular fibrillation. Circulation 82: 2027-2034.

39. Herlitz J, Ekström L, Wennerblom B, Axelsson A, Bång A, et al. (1997) Lidocaine in out-of-hospital ventricular fibrillation. Does it improve survival. Resuscitation 33: 199-205.

40. Roden DM, Woosley RL (1986) Drug therapy. Flecainide. N Engl J Med 315: 36-41.

41. Anno T, Hondeghem LM (1990) Interactions of flecainide with guinea pig cardiac sodium channels. Importance of activation unblocking to the voltage dependence of recovery. Circ Res 66: 789-803.

42. Holmes B, Heel RC (1985) Flecainide. A preliminary review of its pharmacodynamic properties and therapeutic efficacy. Drugs. Springer International Publishing 29: 1-33.

43. Crozier IG, Ikram H, Kenealy M, Levy L (1987) Flecainide acetate for conversion of acute supraventricular tachycardia to sinus rhythm. The American Journal of Cardiology 59: 607-609.

44. Sihm I, Hansen FA, Rasmussen J, Pedersen AK, Thygesen K (1990) Flecainide acetate in atrial flutter and fibrillation. European Heart Journal. The Oxford University Press 11: 145-148.

45. Falk RH (1989) Flecainide-Induced Ventricular Tachycardia and Fibrillation in Patients Treated for Atrial Fibrillation. Ann Intern Med 111: 102-107.

46. Muhiddin KA, Turner P, Blackett A (1985) Effect of flecainide on cardiac output. Clin Pharmacol Ther 37: 260-263.

47. Greenberg HM, Dwyer EM, Hochman JS, Steinberg JS, Echt DS, et al (1995) Interaction of ischaemia and encainide/flecainide treatment: a proposed mechanism for the increased mortality in CAST I. Br Heart J. BMJ Publishing Group Ltd and British Cardiovascular Society 74: 631-635.

48. Echt DS, Liebson PR, Mitchell LB (1991) Mortality and morbidity in patients receiving encainide, flecainide, or placebo: the Cardiac Arrhythmia Suppression Trial. England Journal.

49. The Cardiac Arrhythmia Suppression Trial (1989) Preliminary report: effect of encainide and flecainide on mortality in a randomized trial of arrhythmia suppression after myocardial infarction. 321: 406-412.

50. Carr B, Hawley K, Channer KS (1991) Cardioversion of atrial fibrillation of recent onset with flecainide. Postgrad Med J. The Fellowship of Postgraduate Medicine 67: 659-662.

51. Capucci A, Lenzi T, Boriani G, Trisolino G, Binetti N, et al. (1992) Effectiveness of loading oral flecainide for converting recent-onset atrial fibrillation to sinus rhythm in patients without organic heart disease or with only systemic hypertension. Am J Cardiol 70: 69-72.

52. Martínez-Marcos FJ, García-Garmendia JL, Ortega-Carpio A, FernándezGómez JM, Santos JM, et al. (2000) Comparison of intravenous flecainide, propafenone, and amiodarone for conversion of acute atrial fibrillation to sinus rhythm. The American Journal of Cardiology 86 950-953.

53. Donovan KD, Power BM, Hockings B (1996) Intravenous Flecainide Versus Amiodarone for Recent-Onset Atrial Fibrillation. ACC Current Journal.

54. Suttorp MJ, Kingma JH, Lie AHL, Mast EG (1989) Intravenous flecainide versus verapamil for acute conversion of paroxysmal atrial fibrillation or flutter to sinus rhythm. Am J Cardiol 63: 693-696.
55. Camm AJ, Hellestrand KJ, Nathan AW, Bexton RS (1985) Clinical usefulness of flecainide acetate in the treatment of paroxysmal supraventricular arrhythmias. Drugs 4: 7-13.

56. Crijns HJGM, Van Wijk LM, van Gilst WH, KINGMA JH, Van Gelder IC, et al. (1998) Acute conversion of atrial fibrillation to sinus rhythm: clinical efficacy of flecainide acetate. Comparison of two regimens. European Heart Journal. The Oxford University Press 9: 634-638.

57. Alp NJ, Bell JA, Shahi M (2000) Randomised double blind trial of oral versus intravenous flecainide for the cardioversion of acute atrial fibrillation. Heart BMJ Group 84: 37-40.

58. http://www.sciencedirect.com/science/article/pii/S0002914900011280.

59. Oates JA, Wood A, Funck BC (1990) Propafenone. England Journal.

60. Siddoway LA, Thompson KA, McAllister CB, Wang T, Wilkinson GR, et al. (1987) Polymorphism of propafenone metabolism and disposition in man: clinical and pharmacokinetic consequences. Circulation. Lippincott Williams \& Wilkins 75:785-791.

61. Tonn GR, Kerr CR, Axelson JE (1992) In vitro protein binding of propafenone and 5-hydroxypropafenone in serum, in solutions of isolated serum proteins, and to red blood cells. J Pharm Sci 81: 1098-1103.

62. Olm M, Munne P, Jimenez MJ (1989) Severe reactive airways disease induced by propafenone. Chest 95: 1366-1367.

63. Ravid S, Podrid PJ, Lampert S, Lown B (1989) Congestive heart failure induced by six of the newer antiarrhythmic drugs. J Am Coll Cardiol 14: 1326-1330.

64. Santinelli V, Arnese M, Oppo I, Matarazzi C, Maione S, et al. (1993) Effects of flecainide and propafenone on systolic performance in subjects with normal cardiac function. Chest 103: 1068-1073.

65. Schlepper M (1987) Propafenone, a review of its profile. Eur Heart J 8: 27-32.

66. Khan IA (2001) Single oral loading dose of propafenone for pharmacological cardioversion of recent-onset atrial fibrillation. J Am Coll Cardiol 37: 542-547.

67. Teh LK, Bertilsson L (2012) Pharmacogenomics of CYP2D6: Molecular Genetics, Interethnic Differences and Clinical Importance. Drug Metabolism and Pharmacokinetics 27: 55-67.

68. Lynch T, Price A (2007) The effect of cytochrome P450 metabolism on drug response, interactions, and adverse effects. Am Fam Physician 76: 391-396.

69. Azpitarte J, Alvarez M, Baún O, García R, Moreno E, et al. (1997) Value of single oral loading dose of propafenone in converting recent-onset atrial fibrillation. Results of a randomized, double-blind, controlled study. European Heart Journal 18: 1649-1654.

70. Botto GL, Capucci A, Bonini W, Boriani G, Broffoni T, et al. Conversion of recent onset atrial fibrillation to sinus rhythm using a single oral loading dose of propafenone: comparison of two regimens. Int J Cardiol 58: 55-61.

71. Boriani G, Biffi M, Capucci A, Botto GL, Broffoni T, et al. Oral loading with propafenone: a placebo-controlled study in elderly and nonelderly patients with recent onset atrial fibrillation. Pacing Clin Electrophysiol 21:2465-2469.

72. Botto GL, Bonini W, Broffoni T, Molteni S, Lombardi R, et al. (1996) Conversion of recent onset atrial fibrillation with single loading oral dose of propafenone: is in-hospital admission absolutely necessary. Pacing Clin Electrophysiol 19: 1939-1943.

73. Boriani G, Capucci A, Lenzi T, Sanguinetti M, Magnani B (1995) Propafenone for Conversion of Recent-Onset Atrial Fibrillation : A Controlled Comparison Between Oral Loading Dose and Intravenous Administration. CHEST. American College of Chest Physicians 108: 355-358.

74. Boriani G, Biffi M, Capucci A, Botto GL (1997) Oral propafenone to convert recent-onset atrial fibrillation in patients with and without underlying heart disease: a randomized, controlled trial. Annals of Internal journal.

75. Botto GL, Bonini W, Broffoni T, Espureo M, Cappelletti G, et al. (1998) Randomized, crossover, controlled comparison of oral loading versus 
intravenous infusion of propafenone in recent-onset atrial fibrillation. Pacing Clin Electrophysiol 21: 2480-2484.

76. Kowey PR, Marinchak RA, Rials SJ, Filart RA (1997) Intravenous amiodarone. J Am Coll Cardiol 29: 1190-1198.

77. Connolly SJ (1999) Evidence-based analysis of amiodarone efficacy and safety. Circulation. Lippincott Williams \& Wilkins 100: 2025-2034.

78. Vardas PE, Kochiadakis GE, Igoumenidis NE, Tsatsakis AM, Simantirakis EN, et al. (2015) Amiodarone as a First-Choice Drug for Restoring Sinus Rhythm in Patients With Atrial Fibrillation. CHEST. The American College of Chest Physicians 117: 1538-1545.

79. Singh SN, Fletcher RD, Fisher SG (1995) Amiodarone in patients with congestive heart failure and asymptomatic ventricular arrhythmia. England Journal 333: 77-82.

80. Blanc JJ, Voinov C, Maarek M (1999) Comparison of oral loading dose of propafenone and amiodarone for converting recent-onset atrial fibrillation. PARSIFAL Study Group. The American Journal of Cardiology 84: 1029-1032.

81. Peuhkurinen $\mathrm{K}$, Niemelä $\mathrm{M}$, Ylitalo A, Linnaluoto $\mathrm{M}$, Lilja $\mathrm{M}$, et al. (2000) Effectiveness of amiodarone as a single oral dose for recent-onset atrial fibrillation. Am J Cardiol 85: 462-465.

82. Zimetbaum P (2012) Antiarrhythmic drug therapy for atrial fibrillation. Circulation 125: 381-389.

83. Tikosyn (2013) Center for Drug Evaluation and Research 11: 1-69.

84. Manocha P, Bavikati V, Langberg J, Lloyd MS (2011) Coronary Artery Disease Potentiates Response to Dofetilide for Rhythm Control of Atrial Fibrillation. Pacing and Clinical Electrophysiology 35: 170-173.

85. Torp-Pedersen C, Møller M, Bloch-Thomsen PE, Køber L, Sandøe E, et al. (1999) Dofetilide in patients with congestive heart failure and left ventricular dysfunction. Danish Investigations of Arrhythmia and Mortality on Dofetilide Study Group 341: 857-865.

86. Mosller M (1997) Dofetilide in patients with left ventricular dysfunction and either heart failure or acute myocardial infarction: rationale, design and patient characteristics of the DIAMOND studies. Danish Investigations of Arrhythmia and Mortality ON Dofetilide. Clin Cardiol 20: 704-710.

87. Køber L, Thomsen PEB, Møller M, Torp-Pedersen C, Carlsen J, et al. (2000) Effect of dofetilide in patients with recent myocardial infarction and left-ventricular dysfunction: a randomised trial. The Lancet 356: 2052-2058.

88. Singh S, Zoble RG, Yellen L, Brodsky MA, Feld GK, et al. (2000) Efficacy and safety of oral dofetilide in converting to and maintaining sinus rhythm in patients with chronic atrial fibrillation or atrial flutter: the symptomatic atrial fibrillation investigative research on dofetilide (SAFIRE-D) study. Circulation 102: 2385-2390.

89. Abraham JM, Saliba WI, Vekstein C, Lawrence D, Bhargava M, et al (2015) Safety of oral dofetilide for rhythm control of atrial fibrillation and atrial flutter. Circ Arrhythm Electrophysiol 8: 772-776.

90. Brendorp B, Elming H, Jun L, Køber L, Malik M, et al. (2001) Qtc interval as a guide to select those patients with congestive heart failure and reduced left ventricular systolic function who will benefit from antiarrhythmic treatment with dofetilide. Circulation 103: 1422-1427.

91. Pedersen HS, Elming H, Seibaek M, Burchardt H, Brendorp B, et al (2007) Risk factors and predictors of Torsade de pointes ventricular tachycardia in patients with left ventricular systolic dysfunction receiving Dofetilide. Am J Cardiol 100: 876-880.

92. Brumberg G, Gera N, Pray C, Adelstein E, Barrington W, et al. (2013) Frequency of Toxicity With Chemical Conversion of Atrial Fibrillation With Dofetilide. The American Journal of Cardiology 112: 505-508.

93. Cotiga D, Arshad A, Aziz E, Joshi S, Koneru JN, et al. (2007) Acute Conversion of Persistent Atrial Fibrillation During Dofetilide Initiation. Pacing and Clinical Electrophysiology. Blackwell Publishing Inc 30: 1527-1530.

94. Prystowsky EN, Freeland S, Branyas NA, Rardon DP, Fogel RI, et al. (2003) Clinical experience with dofetilide in the treatment of patients with atrial fibrillation. J Cardiovasc Electrophysiol 14: 287-290.
95. Banchs JE, Wolbrette DL, Samii SM, Penny-Peterson ED, Patel PP, et al. (2008) Efficacy and safety of dofetilide in patients with atrial fibrillation and atrial flutter. J Interv Card Electrophysiol 23: 111-115.

96. Bianconi L, Castro A, Dinelli M, Alboni P, Pappalardo A, et al. (2000) Comparison of intravenously administered dofetilide versus amiodarone in the acute termination of atrial fibrillation and flutter. A multicentre, randomized, double-blind, placebo-controlled study. European Heart Journal 21: 1265-1273.

97. Malhotra R, Bilchick KC, DiMarco JP (2014) Usefulness of pharmacologic conversion of atrial fibrillation during dofetilide loading without the need for electrical cardioversion to predict durable response to therapy. The American Journal of Cardiology 113: 475-479.

98. Murray KT (1998) Ibutilide. Circulation 97: 493-497.

99. Lee KS (1992) Ibutilide, a new compound with potent class III antiarrhythmic activity, activates a slow inward $\mathrm{Na}+$ current in guinea pig ventricular cells. J Pharmacol Exp Ther. American Society for Pharmacology and Experimental Therapeutics 262: 99-108.

100. Ellenbogen KA, Stambler BS, Wood MA, Sager PT, Wesley RC, et al. (1996) Efficacy of intravenous ibutilide for rapid termination of atrial fibrillation and atrial flutter: a dose-response study. J Am Coll Cardiol 28: 130-136

101. Stambler BS, Wood MA, Ellenbogen KA, Perry KT, Wakefield LK, et al. (1996) Efficacy and safety of repeated intravenous doses of ibutilide for rapid conversion of atrial flutter or fibrillation. Ibutilide Repeat Dose Study Investigators. Circulation 94: 1613-1621.

102. Vos MA, Golitsyn SR, Stangl K, Ruda MY, Van Wijk LV, et al. (1998) Superiority of ibutilide (a new class III agent) over DL-sotalol in converting atrial flutter and atrial fibrillation. The Ibutilide/Sotalol Comparator Study Group. Heart BMJ Group 79: 568-575.

103. http://www.onlinejacc.org/content/31/6/1414.abstract.

104. Patsilinakos S, Christou A, Kafkas N, Nikolaou N, Antonatos D, et al. (2010) Effect of High Doses of Magnesium on Converting Ibutilide to a Safe and More Effective Agent. The American Journal of Cardiology 106: 673-676

105. McComb JM, McGovern B, McGowan JB, Ruskin JN, Garan H (1987) Electrophysiologic effects of d-sotalol in humans. J Am Coll Cardiol. American College of Cardiology Foundation 10: 211-217.

106. Hohnloser SH, Woosley RL (1994) Sotalol. N Engl J Med 331: 31-38.

107. Anderson JL, Prystowsky EN (1999) Sotalol: An important new antiarrhythmic. Am Heart J 137: 388-409.

108. Hohnloser SH, Meinertz T, Stubbs P, Crijns HJGM, Blanc JJ, et al. (1995) Efficacy and Safety of d-Sotalol, a Pure Class III Antiarrhythmic Compound, in Patients With Symptomatic Complex Ventricular Ectopy : Results of a Multicenter, Randomized, Double-blind, Placebo-Controlled Dose-Finding Study. Circulation 92: 1517-1525.

109. Chung MK, Schweikert RA, Wilkoff BL, Niebauer MJ, Pinski SL, et al. (1998) Is hospital admission for initiation of antiarrhythmic therapy with sotalol for atrial arrhythmias required? Yield of in-hospital monitoring and prediction of risk for significant arrhythmia complications. J Am Coll Cardiol 32: 169-176.

110. Jordaens L, Gorgels A, Stroobandt R, Temmerman J (1991) Efficacy and safety of intravenous sotalol for termination of paroxysmal supraventricular tachycardia. The Sotalol Versus Placebo Multicenter Study Group. Am J Cardiol 68: 35-40.

111. Sung RJ, Tan HL, Karagounis L, Hanyok JJ, Falk R, et al. (1995) Intravenous sotalol for the termination of supraventricular tachycardia and atrial fibrillation and flutter: a multicenter, randomized, doubleblind, placebo-controlled study. Sotalol Multicenter Study Group. Am Heart J 129: 739-748.

112. Zimetbaum PJ, Josephson ME (2005). Amiodarone versus sotalol for atrial fibrillation 353: 627-630.

113. Fedida D, Orth PMR, Chen JYC, Lin S, Plouvier B, et al. (2005) The Mechanism of Atrial Antiarrhythmic Action of RSD1235. J Cardiovasc Electrophysiol 16: 1227-1238. 
Citation: Guhl EN, Jain SK (2017) Antiarrhythmic Medications for Cardioversion and Maintenance of Sinus Rhythm in Patients with Cardiac Arrhythmias: A Review of the Literature. Cardiovasc Pharm Open Access 6: 218. doi:10.4172/2329-6607.1000218

Page 10 of 10

114. Camm AJ, Capucci A, Hohnloser SH, Torp-Pedersen C, Van Gelder IC, et al. (2011) A Randomized Active-Controlled Study Comparing the Efficacy and Safety of Vernakalant to Amiodarone in Recent-Onset Atrial Fibrillation. J Am Coll Cardiol 57: 313-321.

115. Stiell IG, Roos JS, Kavanagh KM, Dickinson G (2010) A multicenter, open-label study of vernakalant for the conversion of atrial fibrillation to sinus rhythm. Am Heart J 159: 1095-1101.

116. Kowey PR, Dorian P, Mitchell LB, Pratt CM, Roy D, et al. (2009) Vernakalant hydrochloride for the rapid conversion of atrial fibrillation after cardiac surgery: a randomized, double-blind, placebo-controlled trial. Circ Arrhythm Electrophysiol 2: 652-659.

117. Pratt CM, Roy D, Torp-Pedersen C, Wyse DG, Toft E, et al. (2010) Usefulness of Vernakalant Hydrochloride Injection for Rapid Conversion of Atrial Fibrillation. The American Journal of Cardiology 106: 1277-1283.

118. Freilich A, Tepper D (1992) Adenosine and its cardiovascular effects. Am Heart J 123: 1324-1328.

119. Lerman BB, Belardinelli L (1991) Cardiac electrophysiology of adenosine. Basic and clinical concepts 83: p11.

120. Camm AJ, Garratt CJ (1991) Adenosine and supraventricular tachycardia. N Engl J Med 325: 1621-1629.
121. DiMarco JP, Sellers TD, Berne RM, West GA, Belardinelli L (1983) Adenosine: electrophysiologic effects and therapeutic use for terminating paroxysmal supraventricular tachycardia. Circulation 68: 1254-1263.

122. DiMarco JP, Sellers TD, Lerman BB (1985) Diagnostic and therapeutic use of adenosine in patients with supraventricular tachyarrhythmias. J Am Coll Cardiol 6: 417-425.

123. Engelstein ED, Lippman N, Stein KM, Lerman BB (1994) Mechanismspecific effects of adenosine on atrial tachycardia. Circulation 89: 2645-2654.

124. DiMarco JP (1990) Adenosine for Paroxysmal Supraventricular Tachycardia: Dose Ranging and Comparison with Verapamil. Ann Intern Med 113: 104-112.

125. Sellers TD, Kirchhoffer JB, Modesto TA (1987) Adenosine: a clinical experience and comparison with verapamil for the termination of supraventricular tachycardias. Prog Clin Biol Res 230: 283-299.

126. Rankin AC, Rae AP, Oldroyd KG, Cobbe SM (1990) Verapamil or Adenosine for the Immediate Treatment of Supraventricular Tachycardia. QJM. The Oxford University Press 74: 203-208. 